\title{
Adaptive organizational and technological modelsin the systems of construction management
}

\author{
Leonid Zelentsov ${ }^{1}$, Liya Mailyan ${ }^{1, *}$, Ivan Triputa ${ }^{1}$ \\ ${ }^{1}$ Don State Technical University, pl. Gagarina, 1, Rostov-on-Don, 344010, Russia
}

\begin{abstract}
The analysis of the existing management systems of investment and construction projects showed that organizational and technological models, used for the development of calendar plans, are static and do not reflect changes in the course of work execution in real-time, this does not allow to synchronize the terms of work execution and supply of resources and it leads to significant losses in the use of workforce and construction machinery. Adaptability of organizational and technological models in the developed intelligent construction management system is provided through the use of special algorithms and models for the disaggregation of planned information and the aggregation of actual information about works, the deviations calculation of the actual characteristics from the planned values, the elaboration and the decision-making of adjusting the model to the organizational and technological normal practically in real-time
\end{abstract}

\section{Introduction}

In modern Russian construction there are frequent delays in terms of construction, the excess of budgets in the projects and low quality products. One of the main reasons of this situation is the poor organization of the production process on the construction site and that leads to a significant loss of workers' time and construction machinery, to an inefficient use of material resources [1,2].The analysis of the existing state of management systems of investment and construction project (ICP) in the Russian Federation allowed to come to the conclusion that models used on the stage of preparation of the building production and calendar planning of the model are static and reflect the organizational and technological solutions only at the moment of conclusion of the contract on the construction project. The monitoring system of organizational and technological models is episodic in nature and does not allow to synchronize the terms of work execution and supply of resources, this leads to significant losses in the use of workforce and construction machinery $[3,4,6]$. The main objective of solving the preparation of building production (PBP) - is to synchronize the resources delivery in time and space on the construction projects using the whole complex of organizational and technological models (OTM) with works of different

\footnotetext{
*Corresponding author 19liechka84@mail.ru
} 
degrees of specification (Table 1). Developing the OTM for the whole construction period of building sand structures on the stage of the PICthe enlarged network modelOTM -1can be used, in which a facility can be taken as a work distinguished as part of the construction or the accounting (estimated) stages.

Table 1. Hierarchy of organizational and technological management models of investment and construction project.

\begin{tabular}{|c|c|c|c|c|}
\hline Planning periods & $\begin{array}{c}\text { Levels of } \\
\text { detail OTM }\end{array}$ & $\begin{array}{l}\text { Type of } \\
\text { model }\end{array}$ & Optimized options & Stage \\
\hline $\begin{array}{c}\text { For the whole } \\
\text { period of } \\
\text { construction of the } \\
\text { set of buildings and } \\
\text { structures }\end{array}$ & $\begin{array}{l}\text { Facility as } \\
\text { part of the } \\
\text { construction, } \\
\text { Accounting } \\
\text { stages (AS) }\end{array}$ & $\begin{array}{c}\text { The enlarged } \\
\text { network } \\
\text { model }\end{array}$ & $\begin{array}{l}\text { Terms of construction } \\
\text { financing. }\end{array}$ & designing \\
\hline $\begin{array}{c}\text { For the whole } \\
\text { period of } \\
\text { construction of the } \\
\text { facility }\end{array}$ & $\begin{array}{c}\text { Structural } \\
\text { elements (SE) }\end{array}$ & $\begin{array}{c}\text { Network } \\
\text { model }\end{array}$ & $\begin{array}{c}\text { Terms of construction, } \\
\text { financing, } \\
\text { need in } \\
\text { material resources }\end{array}$ & $\begin{array}{l}\text { Preparation } \\
\text { of building } \\
\text { production }\end{array}$ \\
\hline Year-quarter & SE & $\begin{array}{c}\text { Network } \\
\text { model }\end{array}$ & $\begin{array}{l}\text { Terms of construction, } \\
\text { financing, } M R \text {, teams of } \\
\text { workers, CM\&M }\end{array}$ & $\begin{array}{l}\text { Current } \\
\text { planning }\end{array}$ \\
\hline Month & SE, works & Linear graph & $\begin{array}{c}\text { Resources: teams of } \\
\text { workers, CM\&M, MR }\end{array}$ & $\begin{array}{l}\text { Strategic } \\
\text { planning }\end{array}$ \\
\hline Week-day & $\begin{array}{l}\text { Works, } \\
\text { processes }\end{array}$ & Linear graph & $\begin{array}{c}\text { Resources: teams of } \\
\text { workers, CM\&M, MR }\end{array}$ & $\begin{array}{l}\text { Strategic } \\
\text { planning }\end{array}$ \\
\hline
\end{tabular}

A part of a building or structure can be as an accounting stage, for example, underground and over ground parts, roofing, internal plumbing, etc. This macro-model is needed to display the order of putting facilities into operation with integrated micro district development or building an industrial complex and the determination of financing volumes for a sufficiently long planning interval $[16,17]$.

\section{Experimental section}

During the development of the work execution project (WEP) and work planning on the site,OTM -2 is used as a work in which a structural element (SE) appears, tied to the divided grid of the building. Description of the spatial reference of SE can be carried out in the form of a formalized system of coordinates $\mathrm{X}, \mathrm{Y}, \mathrm{Z}$, for example, installation of foundations in the $\mathrm{X}-\mathrm{Y}$ axes, erection of bearing walls at the mark $\mathrm{Z}$ in the $\mathrm{X}-\mathrm{Y}$ axis, and in a simplified form, for example, the construction of bearing walls of the ground floor, section 1, etc. In any case, the purpose of breaking down the building on the SE is the ability to follow the organization of management accounting, organizational and technological simulation of production processes (combination or parallelization of works in the process of the work performance).

OTM-2 is used for planning the work for a year-quarter and for the whole period of construction. The network model is calculated with the bypass arc method which allows to use a voluntary codification of work. OTM-2 can be represented as a network graph of the following form (Figure 1)

On the stage of operative planning, covering a month, a week - day, OTM-3 is used in which the structural elements, if necessary, are detailed (disaggregated) to the level of detailed work and processes. In this case, the model is represented as a Gantt's linear graph[16]. 


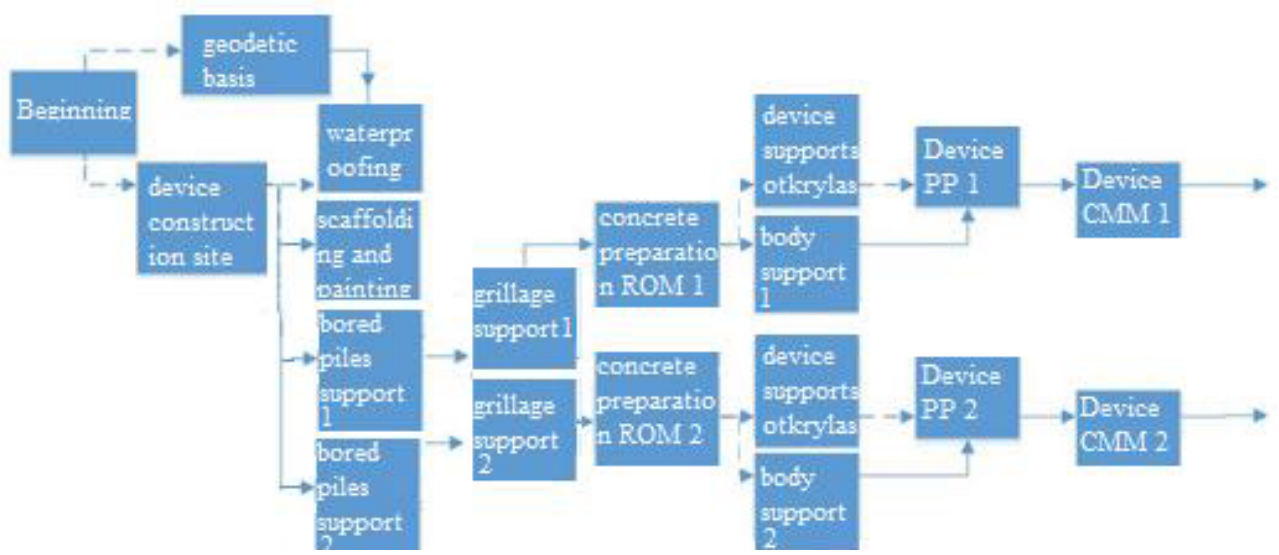

Fig.1. Fragment OTM construction of bridge structures made of reinforced concrete.

OTM adaptability, used in the facility construction is provided through the use of special algorithms for aggregation and disaggregation of planned and actual information about works, the deviations calculation of the actual characteristics from the planned values, the elaboration and the decision-making of adjusting the model to the organizational and technological normal. The complexity of the decision on the OTM adaptation problem is that in case of violation of planned terms of work implementation because of the impact on the system of external and (or) internal factors, time options of the network model must not only be restarted but to carry out a preliminary analysis of the consequences of this decision. This is due to the fact that for each work of network graph, the proposals for the supply of MR are attached, relocation terms of construction machinery and mechanisms $(\mathrm{CM} \& \mathrm{M})$ and terms of workers' teams coming to the site. In case of changing the terms of the work performance, a contractual relationship for the provision of the next amount of work or the contract as a whole, can be violated [13,14,15].

It is necessary to develop the adaptive mechanism to consider all the factors together affecting the productivity and the pace of work. The creation of such an adaptation mechanism is possible with daily records of the actual pace of work and the calculation of its deviations from the planned values.

\section{Results section}

As developed in Don State Technical University (DSTU) the intelligent management system of construction (IMS "Construction") provides a daily calculation of the actual pace of work and the possibility of a preliminary analysis of the effect of variations in the terms of the execution of works on the contractual relationship and the calculation of the possible economic losses. Optimization OTM is possible either by adjustment of the model (combination or parallelization of works), or the intensification of production processes.

Development of the IMS "Construction" is carried out as part of subsystems and automated workplaces (AWP), allowing to simulate the management processes of the following functional areas (Figure 2): preparation of building production; operational management of the construction project; material and technical support of construction projects; management of its own production of concrete and metal products; operation control of machinery and mechanisms; management accounting and budgeting ICP; quality control of the performed work.

The problem of construction company management at the strategic level can be formulated as follows: 


$$
C_{z}-S_{z}^{n}=\Delta P_{z}^{n} \rightarrow \max z \in Z
$$

Where $\mathrm{z}$ - construction object; $\mathrm{Z}$-the number of objects being built at the same time by the construction company; $\Delta \mathrm{P}_{z}^{\Pi}$ - the planned profit of the construction company in the constructions - object; $S_{z}^{\mathrm{H}}-$ the planned cost price of the construction objects at the beginning of the construction; $\mathrm{Cz}$-the cost of construction of the object in accordance with the contract.

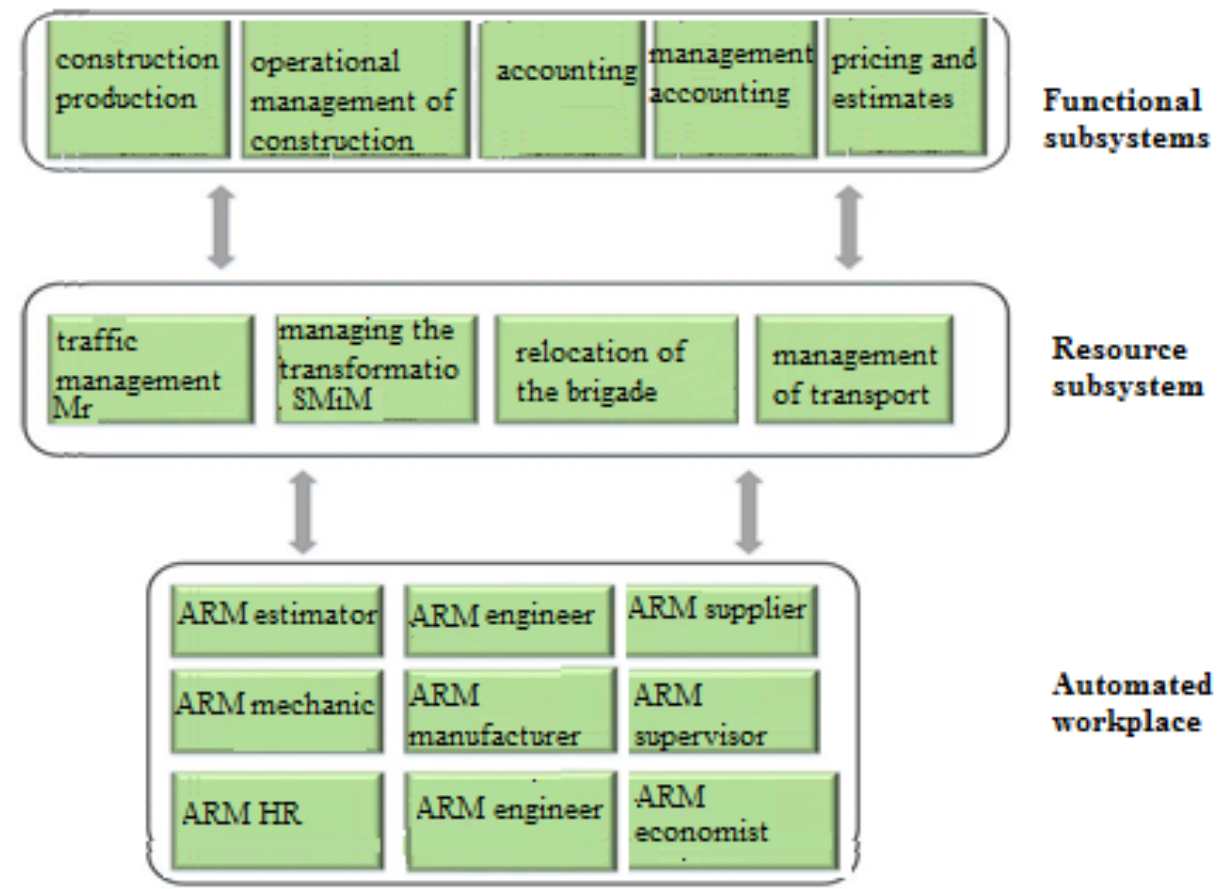

Fig. 2. Decomposition of the IMS "Construction" into subsystems and workstations.

The effectiveness of the organization and management of the building production is characterized by the loss of working hours of workers and construction machinery in the implementation of ICP. Therefore, as a local optimality criterion of efficient management of the construction object, the cumulative loss of time level was adopted in the IMS "Construction" (full interchangeable and inside interchangeable downtime) incurred for a certain period of planning (2).

$$
U_{z}^{\mathrm{H}}=\sum_{t=1}^{T^{p}} \sum_{l=1}^{L} u_{t l z}^{\mathrm{p}} z \in Z
$$

Where $\mathrm{t}$ - working day; $T^{p}$ - period of planning; $\mathrm{L}$-overheads reasons; $u_{l z}^{\mathrm{p}} u_{l z}^{\mathrm{p}}-$ respectively idle workers and construction machinery (loss of non-renewable resources) due to one reason in that day.

\section{Discussion section}

An indicator of the efficiency of the installation works organization at the construction site can serve as a coefficient of working time at the construction works envisaged by the project. 
A distinctive feature of the IMS "Construction" in comparison with other developments in this field is the allocation as a separate subsystem management accounting and budgeting investment and construction project, and the subsystem "Operational management of the construction object " of the program complex (PC) "Foreman".

The reference for the tasks implemented in ARM "Manufacturer of work" (PC "Foreman") is the information coming from the adjacent subsystems (Figure 3):

- ARM Engineer ITM - weekly and daily plan of works;

- ARM HR - lists of workers' teams assigned to the object;

- ARM Mechanic - schedule of construction machinery on the site in the coming week.

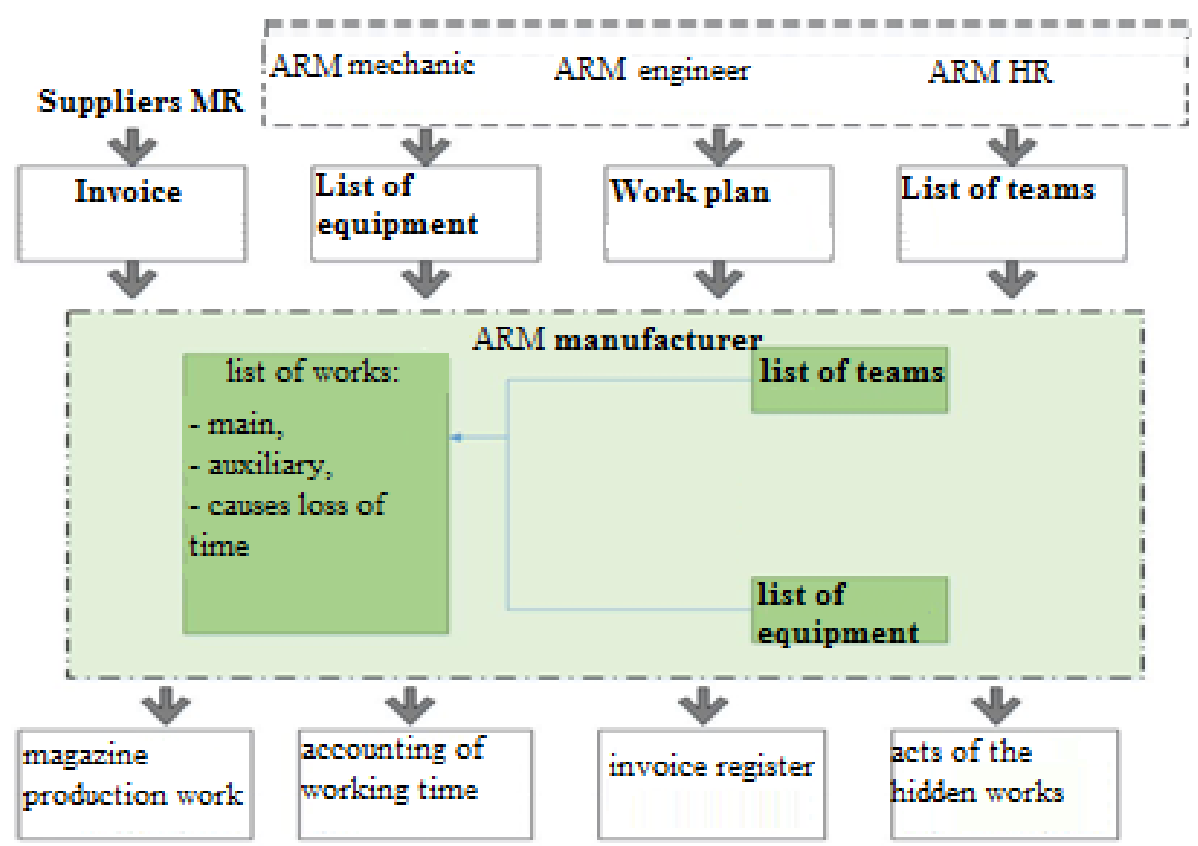

Fig. 3. Schematic diagram of the exchange of information between the control circuits in the ARM "Manufacturer of work".

\section{Conclusions}

The main document on the construction object is the magazine of production work, which contains a list of activities and processes, divided into four groups: the main work; auxiliary works; reasons of working time loss; unforeseen works.

The technology work of PC "foreman" is performed in the following sequence:

- Engineer of Production and Technical Department develops a weekly and daily plan for the next planning period (a week) on the basis of a monthly plan;

- Weekly and daily plan is transmitted by e-mail to the construction object with a fixed number of CE, work processes and an indication of the project and the residual volume at the beginning of the month;

- Foreman cannot correct the composition of work except for procedures for working with unforeseen works;

- Human Resources Department sends a list of teams by email who will work in the planned period.

The main task of the foreman is to complete the table of the report card with wastes of time and an indication of the work on which they were used. 
After entering the information on the report card the labor costs according to the report card and the magazine production work shall be calculated. Until there is a balance of labor costs determined by the report card and the magazine production works the foreman will not be able "to close the day", and send the information to the office of the construction company. In case of hiding the downtime all responsibility will lie with the foreman for failure to comply with the amount of work and as a result of lost productivity, and violation of terms of work performance.

Therefore, the foreman has to show the causes and amount of downtime. In fact, according to such a system the foreman takes pictures of working day activities every day.

The introduction of the PC "foreman" will significantly reduce the entropy of the construction company management and significantly improve the efficiency of management decisions in the buildings construction.

\section{References}

1. N.A.Osadchaya, O.I.Dotsenko, Construction, 45 (2015).

2. N.A. Osadchaya, A.I. Kravchenko, Proceedings of the Rostov State University of Civil Engineering18(18), 126-131 (2014)

3. Y.Z. Zipkin,Adaptation and learning in automatic systems(Nauka,Moscow,1968)

4. N.G.Zagoruiko,Applied methods of data analysis and knowledge(Sobolev Institute of Mathematics, Novosibirsk,1999)

5. L. E. Karpov, V.N. Yudin, ISP RAS Preprint, 18 (2006)

6. V.I. Skurikhin, V.A. Zabrodsky, Y.V. Kopeychenko, Design of adaptive control systems of production (Vishcha School, Kharkiv, 1984)

7. A.A. Zhdanov, Proceedings of the Academy of Sciences 5, 127-134(1999)

8. I.V. Gontareva, M.A. Nemchinov, A.D. Popova,Mathematics and cybernetics in the economy (Economics,Moscow, 1975)

9. A. Bundy,Artificial Intelligence Techniques(Springer, Verlag, 1997)

10. K.D. Althof, E. Auriol, R. Barlette, M. Manago,A Review of Industrial Case-Based Reasoning Tools (AI Intelligence, 1995)

11. S.S. Anand, J.G. Hughes, D.A. Bell, P. Hamilton, Aalborg Denmark, 15-20 (1999)

12. V.V. Kuzmenko, D.V. Grishin, Bulletin NCSTU 2(10), 32 (2003)

13. G.G. Malinetsky, A.B. Potapov, A.V. Podlazov,Nonlinear dynamics: approaches, results(URSS, 2006)

14. E.W. Weisstein, Wolfram MathWorld (2013)

15. Russian Entrepreneurship11, 1 (2008)

16. L.B. Zelentsov, A.L. Zelentsov, K.N. Ostrovsky, N.S. Sankova, Rostov State Civil Engineering University, 73 (2013)

17. L.B. Zelentsov, A.L. Zelentsov, K.N. Ostrovsky,Naukovedenie3(12), 67(2012) 